\title{
Genomics of lactation: role of nutrigenomics and nutrigenetics in the fatty acid composition of human milk
}

\author{
Elizabeth Sosa-Castillo, Maricela Rodríguez-Cruz* and Carolina Moltó-Puigmartí \\ Laboratorio de Nutrición Molecular, Unidad de Investigación Médica en Nutrición, Hospital de Pediatría, Centro Médico \\ Nacional Siglo XXI, Instituto Mexicano del Seguro Social, 06725 Ciudad de México, Mexico \\ (Submitted 19 August 2016 - Final revision received 25 May 2017 - Accepted 9 June 2017)
}

\section{Abstract}

Human milk covers the infant's nutrient requirements during the first 6 months of life. The composition of human milk progressively changes during lactation and it is influenced by maternal nutritional factors. Nowadays, it is well known that nutrients have the ability to interact with genes and modulate molecular mechanisms impacting physiological functions. This has led to a growing interest among researchers in exploring nutrition at a molecular level and to the development of two fields of study: nutrigenomics, which evaluates the influence of nutrients on gene expression, and nutrigenetics, which evaluates the heterogeneous individual response to nutrients due to genetic variation. Fatty acids are one of the nutrients most studied in relation to lactation given their biologically important roles during early postnatal life. Fatty acids modulate transcription factors involved in the regulation of lipid metabolism, which in turn causes a variation in the proportion of lipids in milk. This review focuses on understanding, on the one hand, the gene transcription mechanisms activated by maternal dietary fatty acids and, on the other hand, the interaction between dietary fatty acids and genetic variation in genes involved in lipid metabolism. Both of these mechanisms affect the fatty acid composition of human milk.

Key words: Human milk: Fatty acids: Transcription factors: Lactation: Genomics

Human milk is considered the optimal form of nourishment for infants during the first 6 months of life ${ }^{(1)}$. Human milk is a complex biological fluid containing a wide variety of nutrients and bioactive molecules that contribute to a healthy infant growth and development ${ }^{(2)}$. The composition of breast milk is not constant; some factors known to influence breast milk composition include stage of lactation, parity, gestational age, maternal diet, time of day and time into feeding ${ }^{(3-5)}$. Although some of these variations are physiological and thought to adapt to the needs of the infant (e.g. variations during lactation), other variations (e.g. those resulting from a non-optimal maternal diet) may affect milk's nutritional value and cause child malnutrition, including undernutrition or overnutrition ${ }^{(6)}$.

Nutrients should not be considered only as a source of energy or as factors involved in the development of the organism; nutrients are also able to interact with specific genes $^{(7)}$. Breast milk fatty acids (FA), for instance, provide energy to the breast-fed infant but can also act as structural elements of cell membranes, be precursors of inflammatory mediators and influence gene expression ${ }^{(8-10)}$. In recent years, a new field of study has developed, which combines two different areas of research called nutrigenomics and nutrigenetics. Nutrigenomics explains how nutrients are, either directly or indirectly, able to influence gene expression. Nutrigenetics explains how genes are able to modulate the individual response to nutrients ${ }^{(11)}$. Through both areas of research it may be possible to identify mechanisms that underlie individual variations in dietary requirements, as well as in the capacity to respond to food-based interventions ${ }^{(7)}$.

In this context, the present review is conducted to understand how maternal FA intake modulates the composition of milk fat by interacting with maternal genes (nutrigenomics), and how maternal genes modulate the effect of maternal FA intake on milk fat (nutrigenetics). First, we describe the role and origin of breast milk FA, and then we provide information on the importance of nutrigenomics and nutrigenetics in influencing breast milk's FA composition.

\section{Methods}

Information on the mammary gland development, the role and sources of human milk FA and the role of genetic polymorphisms on milk from ruminant animals was obtained from observational and intervention studies and (systematic) reviews gathered via the electronic databases PubMed platform, EMBASE, Cochrane Library and Medline.

Abbreviations: ALA, $\alpha$-linolenic acid; CHREBP, carbohydrate response element binding protein; FA, fatty acid; ELOVL, elongase; FADS, fatty acid desaturase; LA, linoleic acid; n-3 LC-PUFA, n-3 long-chain PUFA; TFA, trans-fatty acids; SREBP, sterol-regulatory element binding protein.

* Corresponding author: M. Rodriguez-Cruz, fax +52 56276944, email maricela.rodriguez.cruz@gmail.com 
For the sections of nutrigenomics and nutrigenetics of breast milk FA, we undertook a comprehensive review of the literature via the same above-mentioned databases for the period 2005-2017 using the terms 'nutrigenetics', 'nutrigenomics', 'human milk composition', 'fatty acids', 'breast-feeding', 'maternal diet', 'polymorphisms', 'gene-diet interaction' and 'gene expression'. Some older references were also included if they were needed to provide background knowledge (e.g. Nara et al. ${ }^{(52)}$ were among the first researchers to identify the sterol-regulatory elements (SRE) in the human fatty acid desaturase (FADS2) promoter). Moreover, a study carried out by Del Prado et al. ${ }^{(31)}$ provided an overview of the various factors (diet, endogenous synthesis and body reserves mother) that may influence the composition of breast milk. The fundamental inclusion criterion was experimental and updated studies published in English.

\section{Mammary gland development and human milk fatty acids Mammary gland development}

Human milk is produced in the mammary gland, which is composed of glandular tissue (lactocytes), connective and adipose tissue and vascular stroma. The mammary epithelium is composed primarily of two types of differentiated epithelial cells: luminal secretory cells and a layer of basal myoepithelial cells. A network of branching longitudinal striated cells called myoepithelial cells surrounds the alveoli and the smaller ducts $^{(12)}$. Contraction of these cells squeezes the alveoli and causes ejections of milk into the main duct (lactiferous) localised behind the nipple ${ }^{(13)}$.

Mammary gland development begins at puberty and continues throughout pregnancy until lactation. There are four defined stages involved in the mammary gland development: mammogenesis, lactogenesis, galactopoiesis and involution ${ }^{(14)}$. The proportion of macronutrients and micronutrients from human milk progressively changes with the onset and duration of lactation. There are three phases of milk: colostrum, transitional and mature milk, each with distinct characteristics ${ }^{(3,15)}$.

\section{Role of milk fatty acids}

Among the major components of human milk, fat is the second largest component and has a very important role in infant's development as a source of energy and essential lipids ${ }^{(16,17)}$. The main components of milk fat are FA, which are mainly found in the form of TAG. TAG account for $98 \%$ of milk fat ${ }^{(18)}$. FA can be saturated or unsaturated depending on the presence of double bonds. The importance of fat in breast milk as a main source of energy and essential lipid-soluble vitamins and in optimum infant development has been reported ${ }^{(3,9,19)}$. FA also participate in transcriptional regulation of biosynthesis of lipoproteins from the liver ${ }^{(20)}$, promoting successful lipoprotein metabolism in infants. On the other hand, $n$ - 3 long-chain PUFA ( $n$-3 LC-PUFA) are important components of the brain and the retina $^{(21-23)}$ and their deficiency during brain maturation reduces plasticity and compromises brain function in adulthood ${ }^{(24)}$. Several studies suggest that maternal intake of omega-3 LC-PUFA during pregnancy may have favourable effects enhancing cognitive functions and attention in the infant ${ }^{(25,26)}$.

\section{Sources of breast milk fatty acids}

The FA secreted in breast milk have different origins: FA up to C14: 0 originate from de novo synthesis in the breast, whereas FA with a chain length greater than $\mathrm{C} 14: 0$ originate from the maternal diet or body stores ${ }^{(27)}$. Linoleic acid (LA) and $\alpha$-linolenic acid (ALA) are essential FA, which means that they cannot be synthesised in the human body and therefore need to be obtained through the diet. The rest of the FA can be synthesised de novo and are therefore considered non-essential. MUFA contain a single double bond ${ }^{(28)}$ and LC-PUFA have more than eighteen to twenty carbon atoms and more than one double bond; they can be synthesised de novo, mobilised from adipose tissue or obtained from dietary fat (e.g. olive oil, meat, fish) ${ }^{(28-30)}$. The role of the de novo synthesis, diet and mobilisation of body stores are described shortly in the following paragraphs.

\section{De novo synthesis}

De novo synthesis of SFA and MUFA involves the enzyme fatty acid synthase (FAS) and stearoyl-CoA desaturase (SCD), respectively ${ }^{(31,32)}$. PUFA can be classified into two main families, $n-6$ and $n-3$, depending on the position of the first double bond counting from the methyl end group of the $\mathrm{FA}^{(33)}$. As mentioned above, LA and ALA cannot be synthesised de novo by humans and therefore need to be supplied through the diet. The remaining $n-6$ and $n-3$ PUFA can be synthesised from the precursors LA and ALA through a series of elongation and desaturation reactions. LA is metabolised to AA, whereas ALA is metabolised to EPA and DHA as active metabolic products $^{(34)}$ (Fig. 1).

\section{Maternal diet}

Maternal diet influences the FA composition of breast milk, with changes appearing within $8-10 \mathrm{~h}$ after a meal intake and contributing to approximately $30 \%$ of total milk FA. The kind and

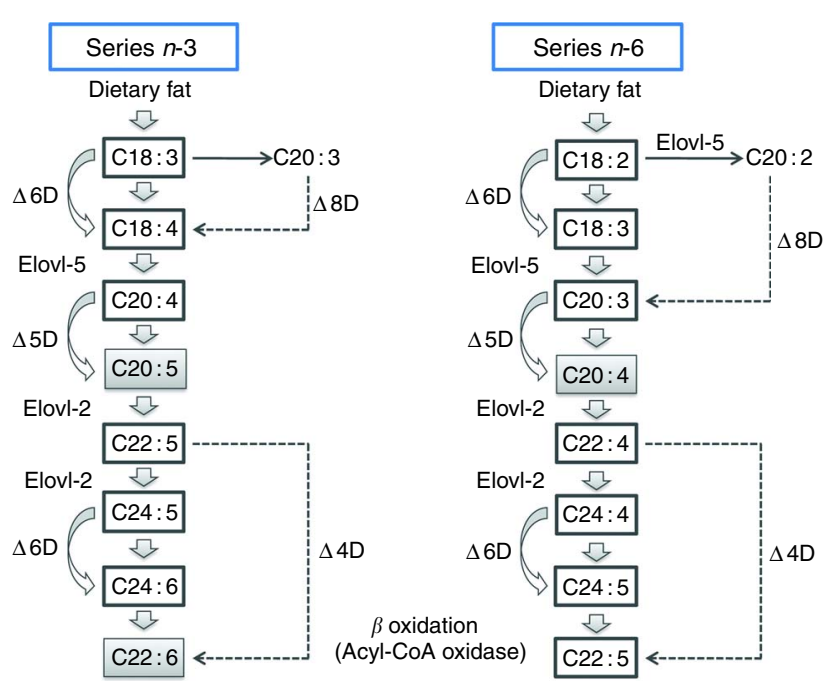

Fig. 1. Synthesis of long-chain PUFA from linoleic acid or a-linolenic acid, showing the steps catalysed by $\Delta 5$ and $\Delta 6$ desaturases. -----, Routes not known to occur in humans. 
levels of FA in breast milk can be modified by changes in dietary fat or energy intake. As demonstrated by Nasser et al. ${ }^{(27)}$ in lactating women, breast milk medium-chain fatty acid (MCFA) concentrations were significantly higher when a lowfat, high-carbohydrate diet was consumed. These changes in MCFA concentrations suggest de novo FA synthesis from carbohydrates. In addition, incorporating fish into the diets of nursing mothers during lactation contributes to an increase of EPA, DPA and DHA in human milk ${ }^{(35)}$

Trans-fatty acids (TFA) are FA found mainly in industrial partially hydrogenated oils and derived products (e.g. margarines, spreads, baked goods and fast foods). They are also found in meat and milk from ruminant animals (coming from production by bacterial metabolism of PUFA in the rumen) ${ }^{(36)}$. Maternal TFA intake is also reflected in breast milk ${ }^{(37)}$.

\section{Mobilisation of maternal body stores}

The composition of human milk can be affected by the maternal nutritional status as well ${ }^{(38)}$. In cases of severe energy restriction, body fat is mobilised, for energy, and the composition of breast milk resembles that of maternal body fat stores. We found that, in lactating women who habitually ate a low-fat diet, the LA secreted in milk was not derived from direct intestinal absorption, suggesting that an important proportion of LA came from the maternal body pool. Turnover of maternal body stores seems to be the major source of milk LA in these women ${ }^{(39)}$. Conversely, recent studies realised in obese rats have demonstrated that the combination of maternal obesity and increased fat intake during gestation and lactation induces alterations in maternal liver metabolism ${ }^{(40)}$ and adversely changes maternal milk fat concentration ${ }^{(41)}$. For example, Panagos et al. ${ }^{(42)}$ reported that the breast milk from obese mothers had a higher $n-6$ to $n-3$ FA ratio and lower concentrations of DHA and EPA compared with lean mothers.

Parity has also been found to have an important effect on body fat stores. Previous studies have shown that maternal multi-parity may place offspring at a greater risk of decreased accretion of brain DHA if the maternal diet contains insufficient $n$-3 LC-PUFA ${ }^{(43)}$. This may be explained by the depletion of maternal DHA stores.

\section{Nutrigenomics from milk fatty acids}

Recent studies in mammals such as rodents, cows and humans have shown that lipids can regulate gene expression in liver and mammary gland, contributing to maintaining adequate concentrations of SFA, MUFA and PUFA in those tissues ${ }^{(44,50)}$. Dietary lipids may act as regulators of lipogenesis interacting with transcription factors including the nuclear receptors PPAR and the transcription factors sterol-regulatory element binding protein $(\mathrm{SREBP})^{(45,46)}$. Both transcription factors are involved in the regulation of the genes FADS1 and FADS2 (encoding for the enzymes $\Delta 5$ and $\Delta 6$ desaturases, respectively) and the genes $E L O V-2$ and $E L O V-5$ (encoding for the enzymes elongases). PPAR comprise a superfamily including $\operatorname{PPAR} \alpha, \operatorname{PPAR} \gamma$ and $\operatorname{PPAR} \beta / \delta$. Activation of $\operatorname{PPAR} \gamma$ and $\operatorname{PPAR} \beta / \delta$ upregulates the expression of genes involved in de novo FA synthesis, whereas activation of PPAR $\alpha$ upregulates genes that control FA oxidation $^{(47)}$. SREBP are a family of transcription factors that have been characterised as mediators of cellular cholesterol homoeostasis and as regulators of FA biosynthesis and uptake. Three members of the SREBP family, SREBP-1a, SREBP-1c and SREBP-2, have been identified. Although SREBP-1c and SREBP-2 are structurally similar, their regulation in the liver by hormones, nutrients ${ }^{(4)}$ and during postnatal development is quite different ${ }^{(48)}$. It has been discovered that whereas SREBP-2 favours cholesterol synthesis, SREBP-1a and SREBP-1c control FA synthesis, regulating genes including lipoprotein lipase, acetyl-CoA carboxylase $\alpha, F A S, S C D, F A D S 1$ and FADS2, and FA ELOVL-2 and ELOVL- $5^{(48,49)}$. SREBP-1c is synthesised as a larger precursor protein that is anchored to the endoplasmic reticulum. After proteolytic cleavage, the N-terminal domain migrates to the nucleus and activates target genes by binding to $\operatorname{SRE}^{(47)}$

PUFA and their metabolites are the main FA that act at the level of the nucleus in conjunction with these transcription factors to regulate the lipogenic genes mentioned above ${ }^{(47)}$. This occurs mainly when there is a demand for FA - for instance, in pregnancy and lactation ${ }^{(50,51)}$. PUFA reduce the nuclear content of SREBP-1a and 1c by accelerating the decay of SREBP-1C mRNA, therefore lowering the hepatic content of SREBP-1C mRNA and the synthesis of SREBP-1c precursor ${ }^{(52)}$. At the proteolytic processing level, PUFA decrease the mRNA transcription through lowering SREBP-1 binding to SRE on the promoter region of different lipogenic genes such as desaturases and elongases. Interestingly, SRE have been identified in the promoter region of FADS2 $2^{(53)}, E L O V L-5$ and ELOVL-2 ${ }^{(54,55)}$, although this has not been clearly demonstrated in FADS1. It is well recognised that, in liver and extrahepatic tissues that provide LC-PUFA for milk synthesis, the FADS1, FADS2, ELOVL-2 and $E L O V L-5$ genes are regulated by SREBP-1c through dietary lipids ${ }^{(48)}$. This is consistent with the report by Tu et al. ${ }^{(56)}$, who found in rats that a diet containing very low levels of PUFA resulted in elevated hepatic mRNA expressions of FADS 2 and ELOVL-2 genes relative to a diet richer in PUFA.

Our group identified for the first time that SREBP-1c is expressed in adipose tissue and mammary gland ${ }^{(48)}$. In addition, Rudolph et al. ${ }^{(57)}$ found that, in pregnancy, SREBP-1a is expressed at a level about equal to SREBP-1c. However, only SREBP1-c is increased at the onset of lactation. On the other hand, we also found that lactating rats fed a low-PUFA diet (2\% maize oil rich in LA) had, in comparison with those fed a highPUFA diet (10\% maize oil rich in LA), increased expression of SREBP-1C and its target genes FADS1 and FADS2 in mammary tissue and liver. At the same time, there was a reduction in the hepatic expression of $P P A R \alpha$, reducing the oxidation of FA. This was consistent with a higher (1-13C) LA incorporation by the mammary gland in the rats fed the low-compared with the high-lipid diet (26.66 (sD 4.77) v. 12.33 (sD 3.44)\%, respectively) and a higher conversion of the uptaken LA into AA (1.06 (SD 0.43) v. $0.23(\mathrm{SD} 0.07) \%$, respectively) ${ }^{(50)}$. In a recent study, we found that FADS1 and FADS2 mRNA were significantly overexpressed on certain days of pregnancy and lactation in the mammary gland, liver and adipose tissue from rats fed a low-lipid diet compared with rats fed an adequate-lipid diet. 
These results suggest that desaturase- and elongase-mediated LC-PUFA synthesis during pregnancy and lactation is not specific to the liver. The increased mRNA expression of these and other enzymes (FAS and $S R E B P-1 C$ ) in the mammary tissue involved in FA synthesis and regulation suggests an important role of this tissue, especially in mothers deficient in dietary lipids ${ }^{(51)}$. Additional research is necessary to determine whether other key regulators of lipogenesis in the lactating mammary gland exist, such as for example the carbohydrate response element binding protein (CHREBP). CHREBP may be indeed another regulator of lipogenesis in the mammary gland, as a high intake of the trans-10, cis-12 isomer of conjugated linoleic acid (18:2 trans-10, cis-12) has been shown to reduce CHREBP mRNA expression, as well as lipogenesis ${ }^{(58)}$.

The effects of maternal TFA intake on the FA composition of breast milk differ depending on the type of isomer. Industrially produced TFA intake affects the milk FA composition negatively, and this occurs through various mechanisms: effects on gene expression or inhibition of the desaturation of LA and ALA to AA and DHA, respectively, in the mammary gland, with potential adverse effects on infant health ${ }^{(59-61)}$. Previous studies have demonstrated that an excessive CLA and VA intake may reduce the milk's fat density. This is explained because these ruminant-produced TFA are able to inhibit the expression of lipogenic genes related to FA synthesis ( $A C A C A, F A S)$, FA desaturation (SCD1, SCD2), TAG esterification (AGPAT1) and transcriptional factors $(S R E B P-1 C \text { and } C H R E B P)^{(59)}$; this process has been called milk fat depression (Fig. 2).

The scientific evidence presented above suggests that maternal dietary FA partly determine the FA composition of human milk by modulating gene expression of key transcription factors such as SREBPS, PPAR and CHREB, among others. During lactation, these transcription factors regulate FA synthesis and oxidation; therefore, those mechanisms are triggered to face the demands of the newborn for development and growth.

\section{Nutrigenetics from milk fatty acids}

The impact of genetic variation on milk FA composition has been (and continues to be) widely explored in cows and other ruminant animals. Quantitative trait loci mapping studies have helped to identify genomic regions associated with milk fat composition and to select candidate genes within these regions for further study ${ }^{(62,63)}$. Candidate gene studies have indeed shown that SNP in selected genes are associated with the FA composition of milk ${ }^{(64-70)}$. The goal behind such studies has been generating the knowledge needed to be able to use selective breeding (together with nutritional manipulation) to breed animals that produce milk with an 'improved' FA composition. 'Improved' composition in this context means a composition that is healthier for humans on the one hand and able to satisfy practical consumer demands on the other (e.g. butter with better spreadability). Nowadays, the focus lays on enhancing the content in milk of C18 MUFA and that of PUFA, particularly EPA, DHA and CLA ${ }^{(71-73)}$.

Studies on the impact of genetic variation on human milk FA composition are instead scarce. They probably only started after the first associations between SNPs and proportions of FA (namely, LC-PUFA) in blood and/or tissues had been reported. Schaeffer et $a l .{ }^{(74)}$ were the first ones to show that common SNPs in the genes coding for FADS were associated with percentages of LC-PUFA in plasma phospholipids. These results were later confirmed by others ${ }^{(75-81)}$. At the same time, Rodriguez-Cruz et al. ${ }^{(48)}$ had demonstrated that fatty acid desaturases were present in the rat mammary gland, raising the question as to whether desaturases were also present in the human mammary gland for the synthesis of LC-PUFA to be secreted into breast milk. Triggered by these findings, Xie \& Innis ${ }^{(80)}$ and Moltó-Puigmartí et $a l^{(81)}$ investigated and demonstrated that FADS SNP were not only associated with LC-PUFA levels in human plasma as Schaeffer et al. ${ }^{(74)}$ had

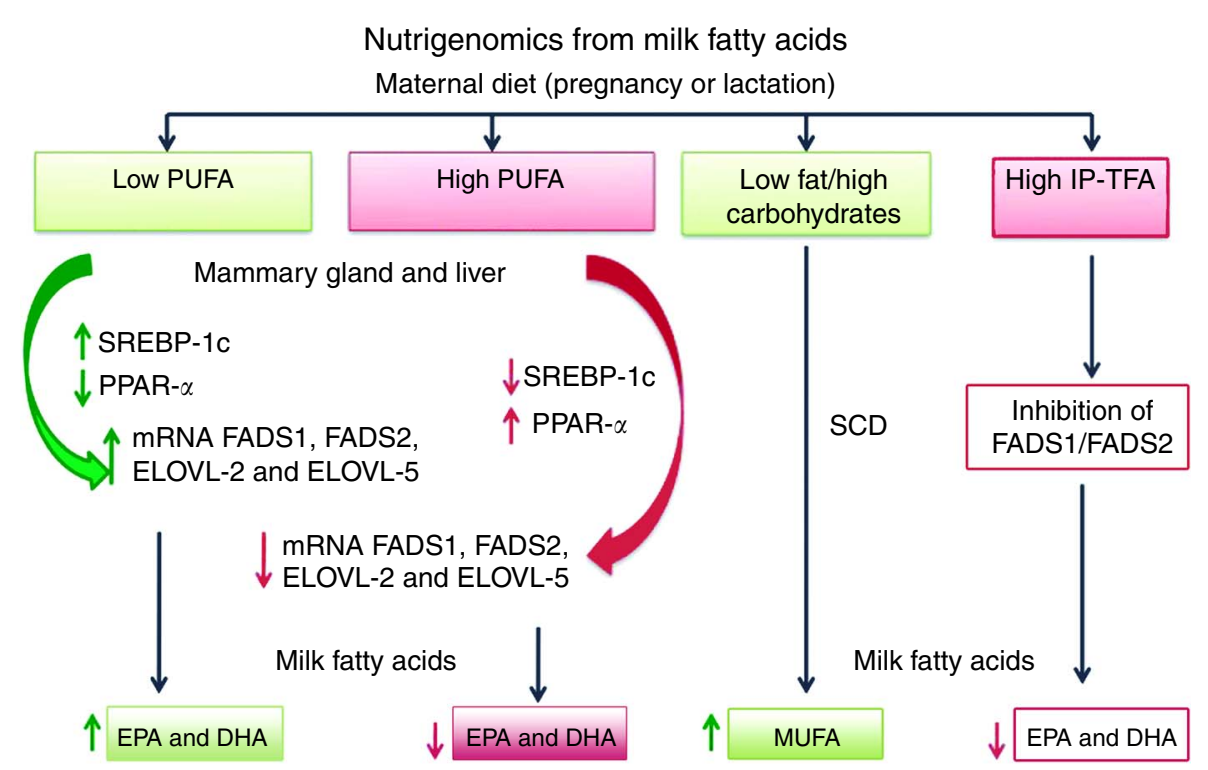

Fig. 2. Nutrigenomics from milk fatty acids. The effect of low or high amount of PUFA and high quantity of industrially produced trans-fatty acids (IP-TFA) from maternal diet on fatty acid desaturases (FADS1, FADS2), elongases (ELOVL-2, ELOVL-5), sterol-regulatory element binding protein-1 (SREBP-1C), stearoyl-CoA desaturase (SCD) and PPARa mRNA expression levels in liver and mammary gland during the pregnancy or lactation. 


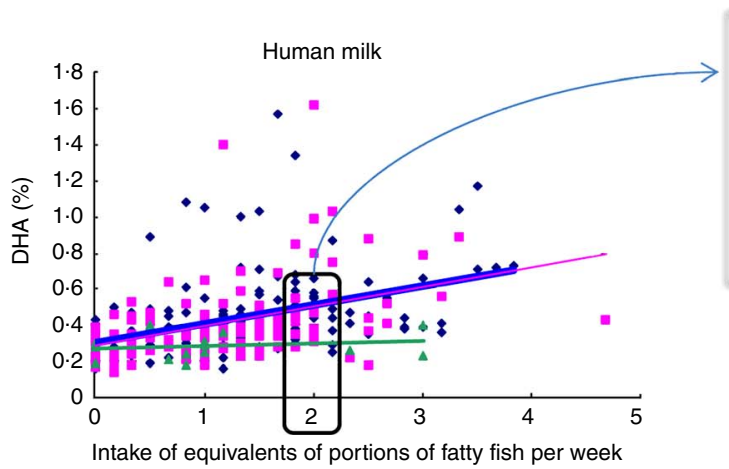

At the recommended intake of 2 portions of fish per week, carriers of the major allele (blue and pink lines, with positive slopes) have about $0.5 \%$ of total fatty acids in their milk as DHA. Instead, the proportion of DHA in minor allele homozygotes (green line, with flat slope) is of about $0.3 \%$ of total fatty acids, irrespective of fish intake

Fig. 3. Breast milk DHA proportions as a function of maternal fatty fish and fish oil intake. Regression lines for major allele homozygous women are represented.

shown but also with LC-PUFA levels in breast milk ${ }^{(80,81)}$. Namely, women homozygous for the minor alleles had lower $\mathrm{AA}$ and DHA proportions in their plasma and breast milk than women carrying the major allele. Moreover, Moltó-Puigmartí et $a l .{ }^{(81)}$ found that FADS SNP modified the effect of fish intake on breast milk DHA levels; concretely, DHA increased with DHA (i.e. fish) intake in women carrying the major allele but not in women homozygous for the minor allele, at least up to the observed intake level (Fig. 3$)^{(81)}$. This finding is of public health interest given that the supply of LC-PUFA to the child during lactation is key for a proper (neuro)development, and breast-fed children from women homozygous for the minor allele could be therefore in a certain disadvantage compared with children from women carrying the major allele. In the years following these first findings, three additional studies have confirmed the association of FADS SNP with breast milk $\mathrm{FA}^{(82-84)}$. Moreover, two studies have shown that also SNPs on the genes coding for the enzymes elongases (namely, ELOVL-2 and $E L O V L-5)$ are associated with the proportions of PUFA in breast milk ${ }^{(82,85)}$. It is to be expected that, with the development of genotyping techniques and the knowledge on FA metabolism, new genetic variants associated with breast milk FA composition will be discovered in the near future. To the best of our knowledge, replication of the gene-diet interaction described by Moltó-Puigmartí et al. has not yet been attempted. However, such an interaction illustrates the possibility that genetic variants contributing to the variability of human milk (FA) composition interplay with maternal diet, bringing the opportunity to modify (i.e. improve) the composition of breast milk through nutrigenetics.

\section{Discussion and conclusions}

Human breast milk is an optimal food for infants because it contains a wide variety of nutrients and bioactive molecules that contribute to healthy growth and (neuro)development. Several studies have shown that maternal nutrition during pregnancy and lactation affects milk composition and hence influences infant's development. In this paper, we review the role of nutrigenomics and nutrigenetics on breast milk FA composition. On the one hand, FA from maternal diet are able to interact directly or indirectly with some transcription factors including the nuclear receptor PPAR, SREBP and CHREBP. This interaction produces changes in the composition of milk. For example, SREBP and its target genes FADS1, FADS2, ELOVL-2 and ELOVL-5 are regulated by the maternal intake of PUFA to maintain adequate concentrations of PUFA in human milk. Instead, industrially produced TFA intake affects the milk FA composition negatively and may have adverse effects on growth and development by interfering with essential FA metabolism. On the other hand, SNP in the FADS and ELOVL genes are associated with PUFA levels in breast milk, and may affect the maternal response to FA intake.

\section{Acknowledgements}

This research received no specific grant from any funding agency, commercial or not-for-profit sectors.

M. R.-C. was in charge of the interpretation of the articles reviewed and manuscript design and editing. E. S.-C. and C. M.-P. had responsibility for research information and manuscript writing. All authors contributed to discuss and had input writing the article. All authors contributed equally to the literature search, analysis of the data published, manuscript writing and revisions of the article. All authors approved the final version of the manuscript.

The authors declare that there are no conflicts of interest.

\section{References}

1. World Health Organization (2011) Exclusive breastfeeding. http://www.who.int/nutrition/topics/exclusivebreastfeeding/en/ (accessed April 2016).

2. Hill DR \& Newburg DS (2015) Clinical applications of bioactive milk components. Nutr Rev 73, 463-476.

3. Ballard O \& Morrow AL (2013) Human milk composition: nutrients and bioactive factors. Pediatr Clin North Am $\mathbf{6 0}$, 49-74.

4. Bachour P, Yafawi R, Jaber F, et al. (2012) Effects of smoking, mother's age, body mass index, and parity number on lipid, protein, and secretory immunoglobulin A concentrations of human milk. Breastfeed Med 7, 179-188.

5. Sinanoglou VJ, Cavouras D, Boutsikou T, et al. (2017) Factors affecting human colostrum fatty acid profile: a case study. PLOS ONE 12, e0175817.

6. Shahrin L, Chisti MJ \& Ahmed T (2015) Primary and secondary malnutrition. World Rev Nutr Diet 113, 139-146. 
7. Verduci E, Banderali G, Barberi S, et al. (2014) Epigenetic effects of human breast milk. Nutrients 24, 1711-1724.

8. Richard C, Lewis ED \& Field CJ (2016) Evidence for the essentiality of arachidonic and docosahexaenoic acid in the postnatal maternal and infant diet for the development of the infant's immune system early in life. Appl Physiol Nutr Metab 41, 461-475.

9. Andreas NJ, Kampmann B \& Mehring Le-Doare K (2015) Human breast milk: a review on its composition and bioactivity. Early Hum Dev 91, 629-635.

10. Mennitti LV, Oliveira JL, Morais CA, et al. (2015) Type of fatty acids in maternal diets during pregnancy and/or lactation and metabolic consequences of the offspring. J Nutr Biochem 26, 99-111.

11. Fenech M, El-Sohemy A, Cahill L, et al. (2011) Nutrigenetics and nutrigenomics: viewpoints on the current status and applications in nutrition research and practice. $J$ Nutrigenet Nutrigenomics 4, 69-89.

12. Arendt LM \& Kuperwasser C (2015) Form and function: how estrogen and progesterone regulate the mammary epithelial hierarchy. J Mammary Gland Biol Neoplasia 20, 9-25.

13. Gardner H, Kent JC, Lai CT, et al. (2015) Milk ejection patterns: an intra- individual comparison of breastfeeding and pumping. BMC Pregnancy Childbirth 15, 156.

14. Riordan J (2010) Anatomy and physiology of lactation. In Breastfeeding and Human Lactation, 4th ed. pp. 79-86 [K Wambach and J Riordan, editors]. Boston, MA: Jones \& Bartlett Learning.

15. Golinelli LP, Del Aguila EM, Flosi Paschoalin VM, et al. (2014) Functional aspect of colostrum and whey proteins in human milk. J Hum Nutr Food Sci 2, 1035.

16. Innis SM (2013) Maternal nutrition, genetics, and human milk lipids. Curr Nutr Rep 2, 151-158.

17. Koletzko B, Agostoni C, Bergmann R, et al. (2011) Physiological aspects of human milk lipids and implications for infant feeding: a workshop report. Acta Paediatr 100, 1405-1415.

18. Mohammad MA \& Haymond MW (2013) Regulation of lipid synthesis genes and milk fat production in human mammary epithelial cells during secretory activation. Am J Physiol Endocrinol Metab 305, E700-E716.

19. Koletzko B (2016) Human milk lipids. Ann Nutr Metab 69 , 28-40.

20. Vallim T \& Salter AM (2010) Regulation of hepatic gene expression by saturated fatty acids. Prostaglandins Leukot Essent Fatty Acids 82, 211-218.

21. Delgado-Noguera MF, Calvache JA, Bonfill Cosp X, et al. (2015) Supplementation with long chain polyunsaturated fatty acids (LCPUFA) to breastfeeding mothers for improving child growth and development. The Cochrane Database of Systematic Reviews, issue 7, Article No. CD007901.

22. De Jong C, Kikkert HK, Seggers J, et al. (2015) Neonatal fatty acid status and neurodevelopmental outcome at 9 years. Early Hum Dev $\mathbf{9 1}, 587-591$

23. Ryan AS, Astwood JD, Gautier S, et al. (2010) Effects of long-chain polyunsaturated fatty acid supplementation on neurodevelopment in childhood: a review of human studies. Prostaglandins Leukot Essent Fatty Acids 82, 305-314.

24. Bhatia HS, Agrawal R, Sharma S, et al. (2011) Omega-3 fatty acid deficiency during brain maturation reduces neuronal and behavioral plasticity in adulthood. PLOS ONE 6, e28451.

25. Smithers LG, Gibson RA, McPhee A, et al. (2008) Higher dose of docosahexaenoic acid in the neonatal period improves visual acuity of preterm infants: results of a randomized controlled trial. Am J Clin Nutr 88, 1049-1056.

26. Jacobson JL, Jacobson SW, Muckle G, et al. (2008) Beneficial effects of a polyunsaturated fatty acid on infant development: evidence from the Inuit of arctic Quebec. J Pediatr 152, 356-364.

27. Nasser R, Stephen AM, Goh YK, et al. (2010) The effect of a controlled manipulation of maternal dietary fat intake on medium and long chain fatty acids in human breast milk in Saskatoon, Canada. Int Breastfeed J 5, 3.

28. Schwingshackl L \& Hoffmann G (2012) Monounsaturated fatty acids and risk of cardiovascular disease: synopsis of the evidence available from systematic reviews and meta-analyses. Nutrients 4, 1989-2007.

29. Hu Y, Tanaka T, Zhu J, et al. (2017) Discovery and finemapping of loci associated with monounsaturated fatty acids through trans-ethnic meta-analysis in Chinese and European populations. J Lipid Res 58, 974-981.

30. Rudolph MC, Monks J, Burns V, et al. (2010) Sterol regulatory element binding protein and dietary lipid regulation of fatty acid synthesis in the mammary epithelium. Am J Physiol Endocrinol Metab 299, E918-E927.

31. Liu H, Liu JY, Wu X, et al. (2010) Biochemistry, molecular biology, and pharmacology of fatty acid synthase an emerging therapeutic target and diagnosis/prognosis marker. Int $J$ Biochem Mol Biol 1, 69-89.

32. Green CD, Ozguden-Akkoc CG, Wang Y, et al. (2010) Role of fatty acid elongases in determination of de novo synthesized monounsaturated fatty acid species. J Lipid Res 51, 1871-1877.

33. Abedi E \& Sahari MA (2014) Long-chain polyunsaturated fatty acid sources and evaluation of their nutritional and functional properties. Food Sci Nutr 2, 443-463.

34. Bazinet RP \& Layé S (2014) Polyunsaturated fatty acids and their metabolites in brain function and disease. Nat Rev Neurosci 15, 771-785.

35. Quinn EA \& Kuzawa CW (2012) A dose-response relationship between fish consumption and human milk DHA content among Filipino women in Cebu City, Philippines. Acta Paediatr 101, 439-445.

36. Stender S, Astrup A \& Dyerberg J (2008) Ruminant and industrially produced trans fatty acids: health aspects. Food Nutr Res 52, 10.3402/fnr.v52i0.1651.

37. Friesen R \& Innis SM (2006) Trans fatty acids in human milk in Canada declined with the introduction of trans fat food labeling. J Nutr 136, 2558-2561.

38. United Nations International Children's Emergency Fund (2009) Tracking progress on child and maternal nutrition. https://www.unicef.org/publications/files/Tracking_Progress_ on_Child_and_Maternal_Nutrition_EN_110309.pdf (accessed April 2017).

39. Del Prado M, Villalpando S, Elizondo A, et al. (2001) Contribution of dietary and newly formed arachidonic acid to human milk lipids in women eating a low-fat diet. Am J Clin Nutr 74, 242-247.

40. Bautista CJ, Montaño S, Ramirez V, et al. (2016) Changes in milk composition in obese rats consuming a high-fat diet. BrJ Nutr 115, 538-546.

41. Saben JL, Bales ES, Jackman MR, et al. (2014) Maternal obesity reduces milk lipid production in lactating mice by inhibiting acetyl-CoA carboxylase and impairing fatty acids synthesis. PLOS ONE 9, e98066.

42. Panagos PG, Vishwanathan R, Penfield-Cyr A, et al. (2016) Breastmilk from obese mothers has pro-inflammatory properties and decreased neuroprotective factors. J Perinatol 36, 284-290.

43. Ozias MK, Carlson SE \& Levant B (2007) Maternal parity and diet ( $n$-3) polyunsaturated fatty acid concentration influence accretion of brain phospholipid docosahexaenoico acid in developing rats. J Nutr 137, 125-129. 
44. Ibeagha-Awemu EM, Li R, Ammah AA, et al. (2016) Transcriptome adaptation of the bovine mammary gland to diets rich in unsaturated fatty acids shows greater impact of linseed oil over safflower oil on gene expression and metabolic pathways. BMC Genomics 17, 104.

45. Capel F, Rolland-Valognes G, Dacquet C, et al. (2013) Analysis of sterol-regulatory element-binding protein 1c target genes in mouse liver during aging and high-fat diet. J Nutrigenet Nutrigenomics 6, 107-122.

46. Neschen S, Morino K, Dong J, et al. (2007) n-3 Fatty acids preserve insulin sensitivity in vivo in a peroxisome proliferator-activated receptor-alpha-dependent manner. Diabetes 56, 1034-1041.

47. Jump DB, Tripathy S \& Depner CM (2013) Fatty acid-regulated transcription factors in the liver. Annu Rev Nutr 33, 249-269.

48. Rodriguez-Cruz M, Tovar AR, Palacios-Gonzalez B, et al. (2006) Synthesis of long-chain polyunsaturated fatty acids in lactating mammary gland: role of Delta5 and Delta6 desaturases, SREBP-1, PPAR alpha, and PGC-1. J Lipid Res $\mathbf{4 7}$, 553-560.

49. Ito Minoru, Nagasawa Michiaki, Omae Naoki, et al. (2013) A novel JNK2/SREBP-1c pathway involved in insulin-induced fatty acid synthesis in human adipocytes. J Lipid Res $\mathbf{5 4}$, $1531-1540$.

50. Rodriguez-Cruz M, Sánchez R, Bernabe-Garcia M, et al. (2009) Effect of dietary levels of corn oil on maternal arachidonic acid synthesis and fatty acid composition in lactating rats. Nutrition 25, 209-215.

51. Rodriguez-Cruz M, Sánchez R, Sánchez AM, et al. (2011) Participation of mammary gland in long-chain polyunsaturated fatty acid synthesis during pregnancy and lactation in rats. Biochim Biophys Acta 1811, 284-293.

52. Takeuchi Y, Yahagi N, Izumida Y, et al. (2010) Polyunsaturated fatty acids selectively suppress sterol regulatory element-binding protein-1 through proteolytic processing and autoloop regulatory circuit. J Biol Chem $\mathbf{2 8 5}$, 11681-11691.

53. Nara TY, He WS, Tang C, et al. (2002) The E-box like sterol regulatory element mediates the suppression of human Delta- 6 desaturase gene by highly unsaturated fatty acids. Biochem Biophys Res Commun 296, 111-117.

54. Shikama A, Shinozaki H, Takeuchi Y, et al. (2015) Identification of human ELOVL5 enhancer regions controlled by SREBP. Biochem Biophys Res Commun 465, 857-863.

55. Kumadaki S, Matsuzaka T, Kato T, et al. (2008) Mouse Elovl-6 promoter is an SREBP target. Biochem Biophys Res Commun 368, 261-266.

56. Tu WC, Cook-Johnson RJ, James MJ, et al. (2010) Omega-3 long chain fatty acid synthesis is regulated more by substrate levels than gene expression. Prostaglandins Leukot Essent Fatty Acids 83, 61-68.

57. Rudolph MC, Neville MC \& Anderson SM (2007) Lipid synthesis in lactation: diet and the fatty acid switch. J Mammary Gland Biol Neoplasia 12, 269-281.

58. Harvatine KJ, Boisclair YR \& Bauman DE (2014) Liver $x$ receptors stimulate lipogénesis in bovine mammary cell culture but do not appear to be involved in diet-induced milk fat depression in cows. Physiol Rep 2, e00266.

59. Kadegowda AK, Connor EE, Teter BB, et al. (2010) Dietary trans fatty acid isomers differ in their effects on mammary lipid metabolism as well as lipogenic gene expression in lactating mice. J Nutr 140, 919-924.

60. Daud AZ, Mohd-Esa N, Azlan A, et al. (2013) The trans fatty acid content in human milk and its association with maternal maternal diet among lactating mothers in Malaysia. Asia Pac J Clin Nutr 22, 431-442.
61. Innis SM (2006) Trans fatty intake during pregnancy, infancy and early childhood. Atheroscler Suppl 7, 17-20.

62. Schennink A, Stoop WM, Visker MHPW, et al. (2009) Short communication: Genome-wide scan for bovine milk-fat composition. II. Quantitative trait loci for long-chain fatty acids. J Dairy Sci 92, 4676-4682.

63. Stoop WM, Schennink A, Visker MH, et al. (2009) Genomewide scan for bovine milk-fat composition. I. Quantitative trait loci for short- and medium-chain fatty acids. J Dairy Sci $\mathbf{9 2}$, 4664-4675.

64. Mele M, Conte G, Castiglioni B, et al. (2007) Stearoylcoenzyme A desaturase gene polymorphism and milk fatty acid composition in Italian Holsteins. J Dairy Sci 90, 4458-4465.

65. Schennink A, Heck JM, Bovenhuis H, et al. (2008) Milk fatty acid unsaturation: genetic parameters and effects of stearoylCoA desaturase (SCD1) and acyl CoA: diacylglycerol acyltransferase 1 (DGAT1). J Dairy Sci 91, 2135-2143.

66. Conte G, Mele M, Chessa S, et al. (2010) Diacylglycerol acyltransferase 1 , stearoyl-CoA desaturase 1 , and sterol regulatory element binding protein 1 gene polymorphisms and milk fatty acid composition in Italian Brown cattle. J Dairy Sci $\mathbf{9 3}$, 753-763.

67. Nafikov RA, Schoonmaker JP, Korn KT, et al. (2013) Sterol regulatory element binding transcription factor 1 (SREBF1) polymorphism and milk fatty acid composition. J Dairy Sci $\mathbf{9 6}$, 2605-2616.

68. Marchitelli C, Contarini G, De Matteis G, et al. (2013) Milk fatty acid variability: effect of some candidate genes involved in lipid synthesis. J Dairy Res 80, 165-173.

69. Nafikov RA, Schoonmaker JP, Korn KT, et al. (2014) Polymorphisms in lipogenic genes and milk fatty acid composition in Holstein dairy cattle. Genomics 104, 572-581.

70. Tăbăran A, Balteanu VA, Gal E, et al. (2015) Influence of DGAT1 K232A polymorphism on milk fat percentage and fatty acid profiles in Romanian Holstein cattle. Anim Biotechnol 26, 105-111.

71. Ashes JR, Gulati SK \& Scott TW (1997) Potential to alter the content and composition of milk fat through nutrition. J Dairy Sci 80, 2204-2212.

72. Lock AL \& Bauman DE (2004) Modifying milk fat composition of dairy cows to enhance fatty acids beneficial to human health. Lipids 39, 1197-1206.

73. Lanier JS \& Corl BA (2015) Challenges in enriching milk fat with polyunsaturated fatty acids. J Anim Sci Biotechnol 6, 26.

74. Schaeffer L, Gohlke H, Müller M, et al. (2006) Common genetic variants of the FADS1 FADS2 gene cluster and their reconstructed haplotypes are associated with the fatty acid composition in phospholipids. Hum Mol Genet 15, $1745-1756$

75. Malerba G, Schaeffer L, Xumerle L, et al. (2008) SNPs of the FADS gene cluster are associated with polyunsaturated fatty acids in a cohort of patients with cardiovascular disease. Lipids 43, 289-299.

76. Martinelli N, Girelli D, Malerba G, et al. (2008) FADS genotypes and desaturase activity estimated by the ratio of arachidonic acid to linoleic acid are associated with inflammation and coronary artery disease. Am J Clin Nutr 88, 941-949.

77. Rzehak P, Heinrich J, Klopp N, et al. (2009) Evidence for an association between genetic variants of the fatty acid desaturase 1 fatty acid desaturase 2 (FADS1 FADS2) gene cluster and the fatty acid composition of erythrocyte membranes. $\mathrm{BrJ}$ Nutr 101, 20-26.

78. Baylin A, Ruiz-Narvaez E, Kraft P, et al. (2007) alpha-Linolenic acid, Delta6-desaturase gene polymorphism, and the risk of nonfatal myocardial infarction. Am J Clin Nutr 85, 554-560. 
79. Tanaka T, Shen J, Abecasis GR, et al. (2009) Genome-wide association study of plasma polyunsaturated fatty acids in the InCHIANTI Study. PLoS Genet 5, e1000338.

80. Xie L \& Innis SM (2008) Genetic variants of the FADS1 FADS2 gene cluster are associated with altered $(n-6)$ and $(n-3)$ essential fatty acids in plasma and erythrocyte phospholipids in women during pregnancy and in breast milk during lactation. J Nutr 138, 2222-2228.

81. Moltó-Puigmartí C, Plat J, Mensink RP, et al. (2010) FADS1 FADS2 gene variants modify the association between fish intake and the docosahexaenoic acid proportions in human milk. Am J Clin Nutr 91, 1368-1376.

82. Morales E, Bustamante M, González JR, et al. (2011) Genetic variants of the FADS gene cluster and ELOVL gene family, colostrums LC-PUFA levels, breastfeeding, and child cognition. PLOS ONE 6, e17181.
83. Lattka E, Rzehak P, Szabó É, et al. (2011) Genetic variants in the FADS gene cluster are associated with arachidonic acid concentrations of human breast milk at 1.5 and 6 mo postpartum and influence the course of milk dodecanoic, tetracosenoic, and trans-9-octadecenoic acid concentrations over the duration of lactation. Am J Clin Nutr 93, 382-391.

84. Ding Z, Liu GL, Li X, et al. (2016) Association of polyunsaturated fatty acids in breast milk with fatty acid desaturase gene polymorphisms among Chinese lactating mothers. Prostaglandins Leukot Essent Fatty Acids 109, $66-71$.

85. Li X, Gan ZW, Ding Z, et al. (2017) Genetic variants in the ELOVL5 but not ELOVL2 gene associated with polyunsaturated fatty acids in Han Chinese breast milk. Biomed Environ Sci 30, 64-67. 